\title{
The Doctor and the Market: About the Influence of Market Reforms on the Professional Medical Ethics of Surgeons and General Practitioners in The Netherlands
}

\author{
Jolanda Dwarswaard • Medard Hilhorst • \\ Margo Trappenburg
}

Published online: 26 January 2011

(C) The Author(s) 2011. This article is published with open access at Springerlink.com

\begin{abstract}
To explore whether market reforms in a health care system affect medical professional ethics of hospital-based specialists on the one hand and physicians in independent practices on the other. Qualitative interviews with 27 surgeons and 28 general practitioners in The Netherlands, held 2-3 years after a major overhaul of the Dutch health care system involving several market reforms. Surgeons now regularly advertise their work (while this was forbidden in the past) and pay more attention to patients with relatively minor afflictions, thus deviating from codes of ethics that oblige physicians to treat each other as brothers and to treat patients according to medical need. Dutch GPs have abandoned their traditional reticence and their fear of medicalization. They now seem to treat more in accordance with patients' preferences and less in accordance with medical need. Market reforms do affect medical professional principles, and it is doubtful whether these changes were intended when Dutch policy makers decided to introduce market elements in the health care system. Policy makers in other countries considering similar reforms should pay attention to these results.
\end{abstract}

Keywords Medical professional ethics - Market reforms · Surgeons · General practitioners

\footnotetext{
J. Dwarswaard

iBMG, Room WJ 8-47, Erasmus University, Campus Woudestein,

Postbus 1738, 3000 DR Rotterdam, The Netherlands

e-mail: dwarswaard@bmg.eur.nl

M. Hilhorst

Department of Medical Ethics, Erasmus Medical Centre, Postbus 2040,

3000 CA Rotterdam, The Netherlands

e-mail: m.hilhorst@erasmusmc.nl
}

M. Trappenburg (ه)

Utrecht School of Governance, Bijlhouwerstraat 6, 3511 ZC Utrecht, The Netherlands

e-mail: M.J.Trappenburg@uu.nl 


\section{Introduction}

Mid October 2009 general practitioner Sandra Bijl published an article in the Dutch doctors' journal Medisch Contact. She described one of the many dilemmas she faced since the introduction of marketized health care in The Netherlands. Doctor Bijl's practice consists of many immigrant patients, with a low education and a low income. Many of them are single mothers, struggling to keep their families afloat and former refugees who suffered personal losses in their country of origin that they still do not know how to deal with. They visit their family doctor very frequently. Dr. Bijl: "Of course I can just pay attention to their physical pains. Quick service and they will get back very soon. As an entrepreneur I might say that this would be profitable: little effort and lots of benefits for me. But as a human being devoted to her profession this would not satisfy me. One of my patients has been suffering from headaches for the past 12 years. Not because of a tumor, or high blood pressure or bad eyesight, but because her grown up children use their mother as their personal slave. So I listened to her and I talked to her. It took me $30 \mathrm{~min}$, and I will not get paid for all of them. She used to visit me once every fortnight, but since the talk I haven't seen her for months. As an entrepreneur I fail if I deliver this type of care, but as a professional, a conversation like that is very rewarding." [4] abbreviated and translated by the authors).

During the 1990s and the first decade of the twenty-first century many governments in Western European countries introduced market elements in their health care systems. Numerous politicians and policy-makers argued that health care should be 'consumer-driven' and 'consumer-oriented'. Care providers should become entrepreneurial; they should cater according to consumer preferences with regard to prices and quality of care. Several authors have observed that these changes may lead to changes in medical professional ethics. Eliot Freidson points out that the logic of professionalism differs from the logic of market consumerism and from the logic of bureaucratic managerialism. Professionals consider their work a secular calling, not a mere job or a means to maximize their income, as the example of dr Bijl shows. Professionals (and medical doctors are archetypal professionals) are devoted to a transcendent value, such as the health of the patient (which is not the same as fulfilling the patient's wishes). Introducing consumerism or managerialism (or both) may threaten "the soul of professionalism" [9]. Referring to Freidson Duyvendak et al. [7] argue that policy changes may lead to a process of deprofessionalization. Eve and Hodgkin [8] argue that rising consumerism and the creation of an internal market within the British National Health Service will challenge doctors' professional ethics. Krizova observes that marketization and other changes in health care systems may lead to a decline of professional autonomy which might cause "a decrease in altruistic or service-oriented attitudes towards patients" [11] Similar concerns raised by a number of other authors, mostly medical ethicists, are discussed by Randall and Williams [18]. Although there are also some dissenting opinions (e.g. Garrett [10] argues that market principles need not destroy professional ethics because sticking to one's professional ethics might be the most profitable strategy for market actors in the long run and Applbaum [1] questions the use and legitimacy of professional ethics in the first place, thus would not deplore its demise), the general feeling seems to be pessimistic. 
A large part of this literature is theoretical argument. Empirical studies are relatively scarce. In this article we will try to add some empirics to the debate on the relationship between market principles and medical professional ethics.

In our study we set out to ascertain how market reforms have changed medical professional ethics in The Netherlands. Within Western Europe The Netherlands has gone farthest in introducing markets and managed competition in health care (cf. [3, 13, 19]), which makes the country very suitable for an empirical study of the relationship between marketization and medical professional ethics. The details of the new Dutch system as well as its economic effects have been discussed in several other publications $[2,12,14,17,22,23]$. For this study it is important to know that:

- Private insurers have to contract hospitals to deliver medical services. Some of these services still have fixed prices, others (mostly elective surgery: inguinal ruptures, varicose veins, knee operations etc.) are freely negotiable;

- Private insurers have to attract clients by offering attractive packages. These packages may include treatment guarantees (e.g. if you are diagnosed with breast cancer, your health insurer may guarantee that you will get surgery within 2 weeks). These treatment guarantees may diminish physicians' room to manoeuvre with their operating schedules;

- The payment system for general practitioners has been changed, in a much more fee-for-service direction. GPs who perform minor surgeries or who use new diagnostic tools may charge much more for this service than they could before 2006. Policy makers hoped to accomplish a substitution effect as minor surgeries in hospitals are more expensive than similar surgeries in GP practices.

Although the complete overhaul of the insurance system took place in 2006, elements of market competition were introduced before that date. Medical professionals in The Netherlands have a few years of experience with market elements by now.

One year after the new insurance system was adopted the Council for Public Health and Health Care (an advisory council to the government and one of the more fervent proponents of the new system) observed that the introduction of market elements in the Dutch health care system had enlarged the influence of insurers and hospital managers on the attribution and the distribution of health care services. The Council foresaw that further marketization might challenge medical professional autonomy as well as medical ethical principles [6] and admonished policymakers and professionals to be vigilant in this respect. In our research we wanted to find out what kind of market induced phenomena professionals encounter in their daily work, how they feel about them and whether these phenomena would change medical professional ethics.

\section{Method}

We chose to study two specialties within the medical profession that differ with regard to their working conditions: general practitioners (GPs) and surgeons. We assumed that both groups would have been confronted with the effects of 
marketization by now; GPs because their payment system has been changed and surgeons because several operations have become the object of market negotiations and may have been included in treatment guarantee packages.

Dutch GPs work in independent practices in the neighborhood of their patients. Most Dutch citizens have their own GP whom they can consult for health-related problems. Dutch surgeons work in hospitals. Patients are referred to surgeons by their GP (who functions as a gatekeeper to hospital care). Surgical work is more specialized than GP work and involves other contact with patients. We assumed that working conditions might influence the way in which doctors are confronted with elements of marketization. For example: GPs might be confronted most directly with demanding patient-consumers whereas surgeons might have to deal with eager hospital managers, looking for quick wins.

We chose to do qualitative research. This would allow us to ask respondents for all sort examples of marketization they encountered in their work which we could not construe beforehand. Moreover we could ask them to discuss these examples and their ideas about them at length, thus allowing for more insights and more nuance than would have been possible in a written questionnaire.

We performed 27 interviews with surgeons and 28 with general practitioners in 2008 and 2009. We strove to interview both male and female doctors, doctors of different generations, doctors working in different regions of the country (more and less urbanized) and surgeons working in different types of hospitals (academic hospitals where surgeons have a fixed salary as well as smaller hospitals 'in the periphery' where surgeons get paid on a fee for service basis) We did not include surgeons working in newly founded private clinics (zelfstandige behandelcentra) who specialize in certain types of surgery (e.g. cosmetic surgery, eye surgery or varicose vein surgery). Although these newly founded clinics may be considered a direct result of marketization in health care we assumed that medical staff in these clinics would be a special segment of the profession. We wanted to find out how market changes play out for rank and file medical professionals in 'ordinary' settings.

Obviously the number of respondents is too small to establish correlations (such as: surgeons in the periphery are more affected by the marketization of health care than surgeons operating in academic hospitals), but our attempt to achieve variation will at least prevent us from drawing conclusions based on the experiences of one particular type of doctors in one particular hospital or one specific municipality. Table 1 provides an overview of the respondents and their background.

The interviews were semi-structured and part of a broader research project, relating to two other topics besides marketization (the growing percentage of well educated, well informed patients and the growing percentage of female doctors). ${ }^{1}$ With regard to marketization we asked our respondents whether they had noticed any changes in their work as an effect of marketization. Most respondents had an understanding of what marketization meant in the context of Dutch health care in

\footnotetext{
1 See for an outline of the general project http://www.margotrappenburg.nl/onderzoek/project beschrijving\%20juni\%202006.pdf.
} 
Table 1 Overview of respondents

$\begin{array}{lr}28 \text { General practitioners } & 15 \\ \text { Male } & 13 \\ \text { Female } & 9 \\ \text { Between } 25 \text { and } 40 & 8 \\ \text { Between } 40 \text { and } 55 & 11 \\ 55 \text { and older } & 17 \\ \text { Urbanized } & 11 \\ \text { Non urbanized } & \\ 27 \text { surgeons } & 16 \\ \text { Male } & 11 \\ \text { Female } & 9 \\ \text { Between } 25 \text { and } 40 & 9 \\ \text { Between } 40 \text { and } 55 & 9 \\ 55 \text { and older } & 6 \\ \text { Academic hospital (fixed salary) } & 21 \\ \text { Non academic hospital (fee for service) } & \end{array}$

general and their own work in particular, ${ }^{2}$ but for those respondents who asked for a clarification we provided some examples, such as: more competition between care providers, more marketing and public relations, fear of losing customers, shifting priorities. After their first answers we asked our respondents to elaborate. If they had noticed change as a result of marketization we asked them to give examples and to describe their thoughts and feelings about the changes they saw. If they had not noticed any change we would ask them if they had witnessed changes outside their direct environment, that is: in other hospitals, other GP practices, other parts of the country or other specialties.

We did not specifically ask our respondents if they had noticed any bending or breaching of medical professional principles, since such questions would be leading in nature. However, we had considered three specific medical-ethical principles that might change as a consequence of marketization. These principles were:

(1) The principle that physicians should regard other physicians as their 'brothers', a moral norm which might change as a consequence of more and harsher competition among doctors;

(2) The principle that patients ought to be treated according to urgency and medical need, which might change if certain patients come to be more profitable than others and

(3) The 'primum non nocere', first of all do no harm principle, which might change because a more market oriented ethic could make physicians more inclined to 'sell' unnecessary and thus potentially harmful treatments or diagnostic interventions.

\footnotetext{
${ }^{2}$ Of course it is difficult to say whether respondents all had the same idea of marketization. We did not ask our respondents for definitions. However, we asked them to give examples of marketization in their daily work and many of them came up with the same examples.
} 
We will address each of these principles in the presentation of our findings.

The interviews were transcribed verbatim and were then analysed in a two phase model. During the first phase the first author coded the interview material using the computer programme Atlas-ti. Atlas-ti allows the researcher to first establish broad categories and then subdivide these into smaller categories. For our research project we used three broad categories, related to the three topics we wanted to investigate. For this article we selected all interview fragments related to market developments in the health care system (one of the three broader categories). The first researcher coded these fragments in smaller categories.

During the second phase the two other researchers read all interview transcriptions and checked the codes attributed to the interview fragments by the first researcher, so as to enhance the validity of our analysis.

\section{Results}

\section{Change or No Change?}

Before we discuss the findings related to the three different principles it is important to establish whether respondents saw any changes at all in their daily work, related to marketization. Despite the fact that we selected our two professional groups because we assumed that they would have been confronted with marketization directly, a minority of respondents (1 surgeon and 7 GPs) reported that they did not notice any difference caused by marketization in their day to day work. The surgeon and two GPs explained that in certain environments it was possible to ignore the changes.

Many people seem to think, let them talk all they want, we will just do our work (SU JV4).

In [my village] everything stays the same. People still have thirteen children [...] I noticed no great difference. Perhaps changes just go past me (GP JV5, p. $6-7,36){ }^{3}$

Two GPs found that the market elements in the new system were too small to cause any real change, and the remaining three GPs explained that market elements (such as marketing and competition) were also prominent when they first started their professional career.

When I first started [other doctors] were very hesitant. There was certainly no shortage of GPs, so it may be a bit much to say that you had to fight your way in, but for sure there was rivalry in the beginning (GP OM7, p. 38).

Female doctors were competitors back then. When I applied for this practice, there was much resistance among other doctors, because in fact they did not want to have a female colleague (GP OV3, p. 39).

\footnotetext{
3 The page numbers in the references at the end of interview quotations refer to our code books (the interview transcriptions).
} 
All other respondents told us that marketization had changed their work.

\section{Marketing Yourself (Advertising)}

The most important change for surgeons, mentioned by eleven of them, pertained to the fact that they now had to sell themselves, they had to advertise or market their performance. Before the marketization took place the doctors' association in The Netherlands (the KNMG) had always stated that physicians should not draw attention to themselves by advertisements. The doctors' association saw to it that doctors adhered to this rule. The introduction of market elements in Dutch health care not only made the anti-advertisement principle obsolete, it actually made it illegal for the doctors' association to uphold this traditional rule of medical professional ethics. Hence the fact that marketing was often mentioned as a major change is not surprising.

Surgeons described the advent of several ways of marketing in health care. Some of them did a visiting tour among GPs in the neighborhood, so as to encourage these GPs to send their patients to their hospital. ${ }^{4}$ One surgeon reported that his hospital had managed (with quite some effort) to become the first google hit for certain types of operations. Other public relations activities involved publishing advertorials in local newspapers, distributing leaflets, inviting a pop group to sing in the hospital to generate more publicity and buying advertising space on the back of a local bus.

Two surgeons were quite positive about this change of practices:

So yes, well, you may be proud if you perform so well (SU JM1).

I always felt it was a pity that we could do absolutely nothing in terms of advertising. You could not say on the radio: come over here, because we're so good at this or that. So yes, I rather like it that you can promote yourself now. Because you do invest a lot in your work. And then, if you go home nobody knows what good things you've been doing. So it feels good to make that public (SU MV1, p. 12, 13).

Four others did not like the self promotion at all.

So basically you have to show off with your product, and I don't like that at all [...] because I think health care is not something fancy or popular, it's just something that has to be decent all around (SU JV3, p. 6-7).

The remaining surgeons regarded public relations and marketing as developments that were thrust upon them, to which they would have to adjust sooner or later.

I don't really like this whole idea of competition in health care but if we do it all the same, then, perhaps you have to go along, and advertise. I don't

\footnotetext{
${ }^{4}$ Good relations between hospitals and GPs were important before marketization was introduced. However, in the past, it was much more common for GPs to refer patients to the nearest hospital without further ado. These days patients are encouraged to choose a hospital and GPs are supposed to help them choose. This has made GP-hospital specialist relations more important.
} 
particularly look forward to having my picture on a bus, but hey, if you have to, you have to (SU MV5, p. 21).

Among GPs the issue of marketing and commercials was less prominent, although six of them mentioned this effect of marketization. One GP explained how she tried to canvass new patients. She studied websites hosted by real estate companies to find out about new inhabitants in her neighborhood, she placed advertisements in a students' magazine and she distributed leaflets throughout her neighborhood. Most GPs reported matter of factly about this new development.

Two GPs morally disapproved of the changes in professional attitude and behavior.

I just want to be a kind and good doctor to people. But you can't put that in a leaflet. You don't. So what should you advertise then? I would not want an evening clinic or a drivers' license medical examination as attention grabbers for my practice (GP JM2, p. 49).

\section{Shifting Priorities}

Traditional medical professional ethics held that health care should be distributed according to medical need. The Declaration of the Rights of the Patient of the World Medical Association clearly states: "In circumstances where a choice must be made between potential patients for a particular treatment which is in limited supply, all such patients are entitled to a fair selection procedure for that treatment. That choice must be based on medical criteria and made without discrimination" [26]. In The Netherlands politicians orchestrated a public debate on choices in health care during the 1980s and early 1990s which led to a Parliamentary confirmation of the need principle: if choices were necessary, medical care should go to those most in need of it [20]. This principle has been reconfirmed by the Dutch doctors' association ever since [21]. Is this medical professional principle endangered by the market elements in the new health care system?

Ten of the surgeons we interviewed mentioned that the new system made them pay more attention to minor afflictions than they did in the past. Their hospitals had invested in clinical paths and speedy treatment for patients suffering from varicose veins and inguinal ruptures. The standardization of these simple treatments became a number one priority.

We are organizing a clinical path for varicose veins. Together with the dermatologist we are making a protocol. We want to see to it that if a patient comes in he gets an examination straight away and then arrange the next appointment right after that (SU MV3, p. 8).

Young colleagues of mine just announce: we're gonna make a clinical path for varicose veins and we're gonna make big money there (SU DM 3, p. 16).

Less popular but also mentioned occasionally were special clinics for people who had taken a fall, for people with urinary problems, and for obese patients hoping for a stomach reduction. Six surgeons observed that the extra attention for routine surgery was taken away from other patients or other medical duties. 
Of course I am not operating more because of maketization. It's a shift of attention, at best (SU MV2, p. 12).

Right, and because one patient gets a speedy treatment, somebody else who suffers from something else, will be helped later. That seems logical, don't you think? But I don't hear anybody about that (SU OM3, p. 17).

We have indicated that bariatric surgery takes up a lot of time, and that we have less time to spend on oncology. We have asked for extra time in operating theatres to enlarge our capacity. Move bariatric surgery to the evening or to the weekends even. We're working on that (SU JV4, p. 3).

Among GPs investing extra resources seems to be a very prominent effect of marketization. GPs do a lot of things that they did not do before the change of the health care system. To be able to do so they invest in new equipment (tympanometers to be able to measure fluid behind the ear, ECG machines to be able to make cardiograms, sophisticated $24 / 7$ blood pressure meters) and they employ personnel (administrative staff, a physician assistant or another GP). Twelve of our GP respondents mentioned that they had bought new equipment or hired new staff to be able to perform extra medical activities. Whereas surgeons testified about a shift in priorities in favour of patients with minor afflictions, several GPs $(n=5)$ witnessed a change for the better for patients with chronic conditions.

Marketization has led to an improvement in the care for the chronically ill. Diabetes care, but even more clearly for COPD patients (GP MV3, p. 8).

In our practice we see it with diabetics. We do much more now. We test their blood every 3 months. Check all the veins. It sounds much better. People are examined much better (GP MM4, p. 11).

The improvement is probably due to the growing competition in the care for the chronically ill. Diabetics and people with other chronic illnesses can sometimes seek care in special clinics. When that happens, GPs miss them as well as the income they generated.

I think it's a pity that diabetics no longer visit a GP. And that they don't see their GP for their regular check up. Because if you come to your GP with some ordinary condition I can ask you how you're doing otherwise. To me those were the nicest elements of GP practice and I know patients feel the same way (GP OV4, p. 47).

Within GP practice the shift of priorities is much more in accordance with the traditional distribution-according-medical-need principle. Spending extra money on equipment and personnel probably leads to a net enlargement of the total amount of medical care, ${ }^{5}$ whereas the extra attention to people with chronic conditions might conceivably be construed as offering extra care to those most in need (although this remains debatable; if the extra services would be spent on diabetics rather than on

\footnotetext{
5 Research shows that the total amount of GP care as well as the costs involved have risen steadily since the 2006 system change [25].
} 
patients with less common but much more debilitating diseases, this would not hold).

\section{Primum Non Nocere}

One of the first principles of medical professional ethics, featuring prominently in the Hippocratic Oath is primum non nocere: first of all, do no harm. It is a principle that might be challenged by the introduction of market principles in health care. If a patient wants a certain operation which the doctor thinks is unnecessary or futile, should the doctor then go along with the patient's wishes (following the rhetoric of demand driven care), despite the fact that an operation might harm the patient (after all, every surgical procedure involves certain risks), or should the doctor refuse? And what if operating - although useless or unnecessary-would bring money, to the doctor and to the hospital? Six of our surgeon respondents pointed out that this might lead to tensions.

They perform gallbladder surgery here on people with relatively minor complaints. Many people have gallstones and if they are not in much pain, I doubt if an operation will do them much good (SU JM1, p. 4).

Look at oncology. If people suffer from terminal cancer, and you know that an operation won't do any good, many patients will say: all the same, even if there's only one percent chance of success, will you please operate? And as the influence of the market grows, the doctor may say, well, I can sit here and talk for an hour or so, to explain this patient that an operation is pointless. But I may also think: he wants an operation, everybody tells me we ought to deliver patient centred care, so I am politically correct if I operate, I get more money if I operate, and I prefer operating to talking anyway. So what incentive do I have left to explain my patient that he should not undergo surgery? (SU OM1, p. 15).

Another surgeon reported that she would hold firm in this respect.

Sometimes I explain to my patients that surgery would not benefit them. I tell them: 'I like to operate, that's why I chose this profession, I earn money if I operate on you, so sure, I could operate, but it would not be good for you' (SU MV3, p. 9).

Another surgeon pointed out that surgery, unlike other specialties, would not allow for this type of manipulation with indications.

You can't fool around in surgery. You either have an inguinal rupture or you don't. [...] You cannot fake in this profession. It is very difficult to perform unnecessary surgery. It's always been like that. There was a doctor here who specialised in throats and ears. If you do that type of thing you can look in all sorts of body holes and say something about them. Quite easy to cheat. You admit someone; have a look in one of his holes, you say: no lump there and Bob's your uncle (SU MV1, p. 14). 
In Dutch GP practice the do no harm principle used to be interpreted as follows [15]:

- Any medical performance by any doctor is a form of medicalization and thereby potentially harmful.

- If a patient can recover without therapy or medication it is far better to forego treatment.

- If a patient really needs medication or therapy, he should get it, but preferably as little as possible.

- Thus, if a patient can be treated at home by his GP this is to be preferred over hospital treatment. Hospital doctors tend to over treat, a hospital is a sickening environment and hospital treatment takes the patient out of his private surrounding which is unsettling and potentially unhealthy.

This GP interpretation of primum non nocere suited the Dutch government in the 1980s and 1990s. Hospital care is expensive and GPs were strict gatekeepers to hospital care, thus contributing to the government's intention to cut back on medical care. Several GP respondents informed us about the traditional GP ideology.

That really put a mark on Dutch GPs. Don't do anything unnecessary. And I think, this whole idea of let's keep it all affordable, that's also part of what it means to be a GP (GP OM3, p. 53).

It's about being reticent [...] To prevent unnecessary damage. And also because of the costs (GP OM6, p. 27).

Many GP respondents $(\mathrm{n}=22)$ felt that this medical professional principle, their traditional GP ideology, was endangered by the marketization of health care. They were treating conditions that did not really need treatment according to their former ideology. They were performing examinations which they would have condemned as unnecessary in the past.

For instance, say you've got a metal splinter in your eye. If I take it out with a cotton swab I get 9 euros. If I use a tiny drill to get it out, that is classified as a pseudo specialist intervention, and then I get 51 euros. So you see, it's kind of tempting to pick up the drill and get it out like that. While actually it's not necessary, and a drill always creates a little wound... So that's a threshold for a doctor. But I am sure there is more drilling going on than necessary (GP MM1, p. 14).

Colleagues of mine want to invite all patients over 50 in their practice to make an ECG. I find that dubious. [...] The same thing happens with a lung function meter (GP MV2, p. 13).

A full blood examination. In the past I would wonder: what do you want with it? [...] And now I say: okay, patient wants it, fine. I am not the one who's going to pay for it (GP MM3, p. 24).

Some GP respondents reported that they still want to cling to their traditional reticence and that they don't want to give in. 
GP medicine is like rowing upstream. Against the patient's demand even. That may sound strange, because you have to think along with your patient, but I think that patients do ask a lot of unhealthy things (GP OM2, p. 31).

I think you should just hold firm. I sometimes say to a patient, look you're not in a supermarket here where you can come in and just take whatever you want. It doesn't work like that (GP MM3, p. 25).

However, the same GP also told that he felt he had no choice but to give in, because he feared that patients would leave him and find another GP.

The majority of GPs seem to be reinterpreting the do no harm principle. They have discovered that patients are not harmed by examinations and blood tests. Quite the contrary, patients seem to like it (GP MM1, p. 12). GPs have bought equipment which enables them to examine patients in their own office, rather than referring them to a hospital, which contributes to the idea that patients will not be harmed, as patients don't have to spend half a day waiting in a hospital, they can be examined on the spot (GP MV2, p. 10).

Although screenings and examinations do not harm patients and many patients rather like to be examined thoroughly every now and then (GP MM4, p. 13), screenings and examinations do cost a lot of money, while it is unclear whether they will improve public health. In the past the costs of health care were an integral part of the GPs ideology, of their particular interpretation of the do no harm principle. This seems to have changed, due to marketization.

[Politicians] hoped to lower the costs of health care. But what you see is the opposite. There's a rising demand for total body scans and the like. Because everybody wants to have everything and everything is being refunded by health insurers (GP MV 3, p. 55).

You should not make GP care commercial. The minister is completely wrong doing that. [...] Because GPs will then try to please their patients and that is not always what's best for the patient (GP MM4, p. 33).

I think the argument that you should not harm your patient will remain prominent. But cooperating to keep down the costs of health care; that's not appealing any more (GP MM1, p. 29).

\section{Conclusion}

During the 1990s and the first decade of the 21st century a lot of things changed in Dutch health care. Guidelines and standards for medical treatment became more important due to a growing emphasis on evidence based care. Several laws were adopted to strengthen the position of patients and patients' organizations. The economy went up and down, which had repercussions in the health care system. And marketization was introduced. It is difficult, perhaps even impossible to prove that certain developments in daily practice brought up by our respondents (e.g. the changes in diabetic care) were caused by marketization rather than, for example, 
standardization. Some examples may have been triggered or caused by more than one development.

Moreover, we have to be careful drawing conclusions based on a limited number of interviews among just two medical specialties. What holds for surgeons in Dutch hospitals need not necessarily hold for other specialists in Dutch hospitals, let alone hospitals in other countries contemplating market reforms. Still we strove for diversity among our respondents, and we explicitly asked them to relate their own as well as other doctors' experiences with and feelings about the market reforms. Also it seems significant that changes in medical professional ethics have occurred just a few years after the introduction of market reforms. Our research shows that the Dutch Council for Public Health and Health Care and the authors discussed in the introduction were right when they pointed out that the introduction of market elements in health care would challenge traditional medical professional ethics.

The 'do not advertise principle' has been abolished. Marketing activities seem to be widespread in hospital surroundings and some marketing also goes on in GP practices. Both GPs and surgeons are divided about this. Some physicians abhor the self-promotion involved, others welcome the new opportunities, whereas yet others consider this a fact of life, with which they will learn to live eventually.

The 'distribute according to medical need' principle has become less prominent in hospitals. A lot of medical time and energy is spent on minor, routine operations with which hospitals can make a lot of money. This sometimes goes to the detriment of patients in need of major, risky surgical procedures. In GP practices more attention goes to patients with chronic conditions who may arguably qualify as those most in need of medical care.

Lastly, the primum non nocere principle is still being upheld in surgery. Among GPs this principle gradually acquires a whole new meaning. Whereas it used to mean: do not examine or treat a patient unless this is really necessary, it now comes to mean: you may examine and treat a patient as he or she prefers as long as you do not actually harm your patient. The traditional GP ideology, which may be conceived as a very broad interpretation of the Do no harm principle, is challenged most by the market elements in the new system.

Our findings are summarized in Table 2.

Table 2 Summary of findings

\begin{tabular}{lll}
\hline $\begin{array}{l}\text { Principle of } \\
\text { medical ethics }\end{array}$ & Surgeons & GPs \\
\hline $\begin{array}{c}\text { You shall not } \\
\text { advertise }\end{array}$ & $\begin{array}{c}\text { Substantial change: marketing has } \\
\text { become normal although some } \\
\text { surgeons dislike it }\end{array}$ & $\begin{array}{c}\text { Small change: marketing is not very } \\
\text { widespread, but GPs feel (and some fear) } \\
\text { this may change }\end{array}$ \\
$\begin{array}{c}\text { Distribute } \\
\text { according to } \\
\text { medical need } \\
\begin{array}{c}\text { Primum non } \\
\text { nocere }\end{array}\end{array}$ & $\begin{array}{c}\text { Substantial change: much more } \\
\text { attention to minor afflictions }\end{array}$ & $\begin{array}{c}\text { Small change in favour of patients with } \\
\text { chronic conditions, but this may concur with } \\
\text { the moral principle }\end{array}$ \\
to operate more, but do not give in & $\begin{array}{c}\text { Substantial change: the do no harm principle is } \\
\text { reinterpreted. Medical attention is no longer } \\
\text { considered harmful per se }\end{array}$ \\
\hline
\end{tabular}


Obviously it is too early to render a final verdict on the effects of market reforms in the Dutch health care system. Some of our findings have advantages and disadvantages. The advent of advertising due to competition among doctors and hospitals could diminish patients' trust in doctors, but it could also be appreciated as a source of information. As to the other changes, neither of these would have to create immediate problems if the costs of health care were allowed to expand. One could then just pay for the extra time spent on minor surgery and on the growing number of preventive examinations in GP practice, making sure that other patients with other conditions would not have to suffer the consequences. However, recent economic reports have pointed out that marketization has driven up costs and that most of these costs are still paid with public money despite all the market rhetoric $[5,16,24]$. If health care policy makers cannot accept ever rising costs and do not want to defer costs to citizens' private expenses, they should realize that marketization within the boundaries of a public budget causes changes in professional medical ethics. These changes should be weighed and taken into account whenever further policy changes are considered.

Acknowledgments Our study was funded by the Dutch Organization for Scientific Research (NWO).

Open Access This article is distributed under the terms of the Creative Commons Attribution Noncommercial License which permits any noncommercial use, distribution, and reproduction in any medium, provided the original author(s) and source are credited.

\section{References}

1. Applbaum, A. I. (1999). Ethics for adversaries: The morality of roles in public and professional life. Princeton, N.J.: Princeton University Press.

2. Bartholomée, Y., \& Maarse, H. (2007). Empowering the chronically Ill? Patient collectives in the new Dutch health insurance system. Health Policy, 84, 162-169.

3. Bartholomée, Y., \& Maarse, H. (2008). Course and impact of market reform in Dutch health care uncertain. Intereconomics, 43, 189-194.

4. Bijl, S. (2009). Marktwerking haalt hart uit de zorg. Medisch Contact, 64, 1726-1728.

5. Collot d'Escury, T., Alma, R., Van Reenen, M., Van der Zee, S., Groenewegen, M. (2010). De Zeven Zorgen. Ontwikkelingen Nederlandse Ziekenhuizen 2003-2008 en Belangrijkste Aandachtspunten voor de Toekomst. Roland Berger Strategy Consultants. http://www.rolandberger.nl/media/pdf/ Roland_Berger_zorgstudie_20090928.pdf [Internet]. Accessed 18 Mar 2010.

6. Council for Public Health and Health Care. (2007). Vertrouwen in de Arts. [internet] Attainable at: http://www.rvz.net/data/download/RVZ_Vertrouwen_in_arts.pdf.

7. Duyvendak, J. W., Knijn, T., \& Kremer, M. (2006). Policy, people, and the new professional. De-professionalisation and re-professionalisation in care and welfare. Amsterdam: Amsterdam University Press.

8. Eve, R., \& Hodgkin, P. (1997). Professionalism and medicine. In J. Broadbent, M. Dietrich, \& J. Roberts (Eds.), The end of the professions? The restructuring of professional work (pp. 69-85). London: Routledge.

9. Freidson, E. (2001). Professionalism. The third logic. Cambridge: Polity.

10. Garrett, J. (2008). Fostering professional virtue in the market. Reflections on the challenges facing Chinese health care reform. Philosophy and Medicine, 96, 169-180.

11. Krizova, E. (2008). Marketization of health care and changes in the professional status of the medical profession. In N. E. H. M. Zeegers \& H. E. Bröring (Eds.), Professions under pressure. Lawyers and doctors between profit and public interest (pp. 99-111). Den Haag: Boom Juridische Uitgevers. 
12. Lako, C. J., \& Rosenau, P. (2009). Demand-driven care and hospital choice. Dutch health policy toward demand-driven care: Results from a survey into hospital choice. Health Care Analysis, 17, 20-35.

13. Maarse, H. (2006). The privatization of health care in Europe: An eight country analysis. Journal of Health Politics, Policy and Law, 31, 981-1014.

14. Maarse, H., \& Ter Meulen, R. (2006). Consumer choice in Dutch health insurance after reform. Health Care Analysis, 14, 37-49.

15. Mol, A., \& van Lieshout, P. (1989). Ziek is het Woord Niet. Medicalisering, Normalisering en de Veranderende Taal van Huisartsgeneeskunde en Geestelijke Gezondheidszorg, 1945-1985. Nijmegen: SUN.

16. Nederlandse Zorgautoriteit. (2010). Medisch specialistische zorg 2010. Tussenrapportage deel 1. http:// www.nza.nl/104107/105773/Monitor_medisch_specialistische_zorg_2010_-_deel_1.pdf [Internet]. Accessed 18 Mar 2010.

17. Okma, K. G. H. (2008). Learning and mislearning across borders: What can we (Not) learn from the 2006 health care reform in The Netherlands? Commentarty on Roseanau and Lako. Journal of Health Politics, Policy and Law, 33, 1057-1070.

18. Randall, G. E., \& Williams, A. P. (2009). Health care reform and the dimensions of professional autonomy. Canadian Public Administration, 52, 51-69.

19. Rice, T., \& Biles, B. (2000). Reconsidering the role of competition in health care markets: Introduction. Journal of Health Politics, Policy and Law, 25, 863-873.

20. Trappenburg, M. J. (1993). Soorten van gelijk. Medisch-ethische discussies in Nederland. Zwolle: Tjeenk Willink.

21. Trappenburg, M. J. (2009). Verval van een vitale norm. Socialisme en Democratie, 66, 12-18.

22. Vaillancourt Rosenau, P., \& Lako, C. J. (2008). An experiment with regulated competition and individual mandates for universal health care: The New Dutch health insurance system. Journal of Health Politics, Policy and Law, 33, 1031-1055.

23. Vaillancourt Rosenau, P., \& Lako, C. J. (2008). Health insurance experiments in The Netherlands and Switzerland: A rejoinder with updates. Journal of Health Politics, Policy and Law, 33, 1073-1077.

24. Van de Ven, W. P. M. M., Schut, F. T., Hermans, H. E. G. M., de Jong, J. D., van der Maat, M., Coppen, R., et al. (2009). Evaluatie Zorgverzekeringswet en Wet op de zorgtoeslag. Den Haag: ZonMW.

25. Van Dijk, C. E., Verheij, R. A., de Bakker, D. H. (2008). Bekostiging van de huisartsenzorg: Monitor 2006 en eerste halfjaar van 2007 [Internet] www.nivel.nl/pdf/Rapport-Bekostiging-huisartsenzorgMonitor-Text Version. Accessed 27 Sept 2010.

26. WMA. (2005). World medical association medical ethics manual. [Internet] http://www.wma.net/e/ ethicsunit/pdf/manual/ethics_manual.pdf. 